\title{
Workshop on the Development of the CoreWall Suite of Applications
}

by the CoreWall Steering Committee

doi:10.2204/iodp.sd.3.15.2006

\section{Workshop Goals}

The CoreWall project was funded recently (March 2006) by the U.S. National Science Foundation (NSF, ). It is charged to develop a basic suite of data integration and visualization applications for broad use in the ocean-, lake-, continental-, and ice-coring communities. A CoreWall workshop was held on 8-10 May 2006 in Washington, D.C. to explore possible development pathways for the CoreWall Suite of applications. The original CoreWall application was envisioned by the lake-core community who needed a better way to visualize their cores, do visual core descriptions, and share core photos and data in an integrated environment. A collaboration of earth and computer scientists from four universities and one consulting firm was established to accomplish these goals.

To define the appropriate specifications and requirements of the coring communities, the workshop brought together forty-two participants from a variety of ocean and lake drilling groups, such as the Integrated Ocean Drilling Program (IODP), the International Continental Scientific Drilling Program (ICDP), ANDRILL, and LacCore, as well as databases like PetDB, SedDB, and PaleoStrat, application developers from GeoMapApp and Match, web portals such as CHRONOS, educators such as the Science Museum of Minnesota (U.S.A.), and other interested scientists.

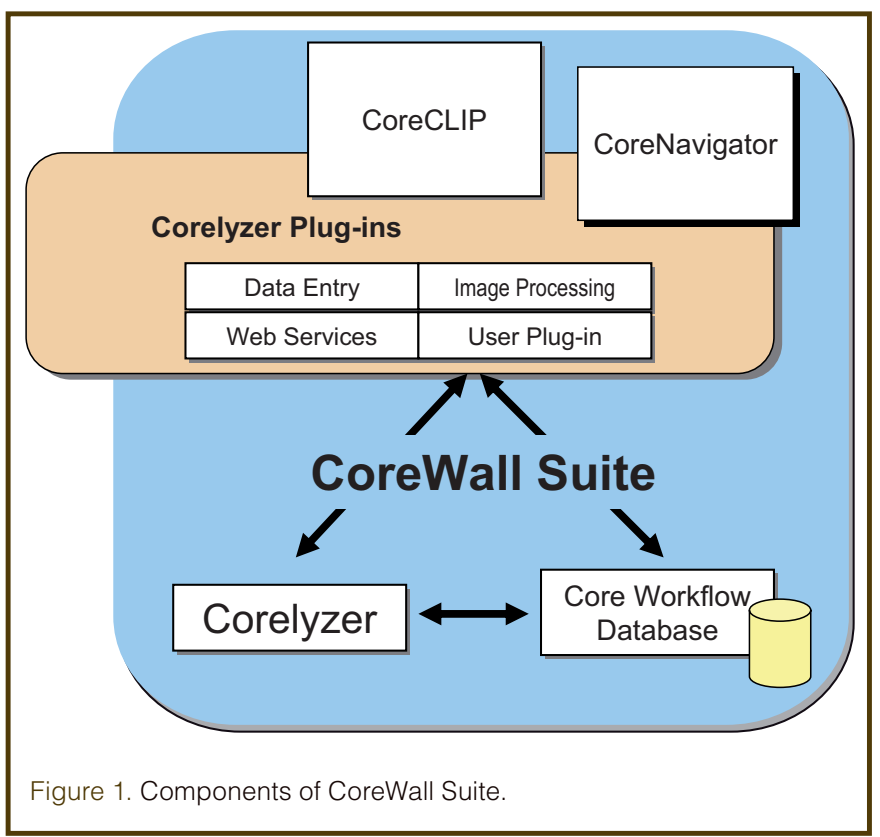

The first goal of the workshop was to introduce the participants to the current stage of CoreWall development. While the name implies something physical and perhaps large, it is actually a group of open-source, cross-platform software applications that have modest hardware requirements and can be used on anything from a laptop to a multi-panel display depending on project needs.

The CoreWall Suite currently consists of four parts, each having a different purpose for viewing, integrating, or exploring data (Fig. 1):

1) The Corelyzer is the primary visual integration workspace that allows users to view depth-registered data and images from any compatible database. At the workshop, the data and images from Ocean Drilling Program (ODP) Leg 199 and from ICDP/NSF Lake Titicaca drilling project were used as examples of how the Corelyzer can scale from medium- to large-scale projects and handle large datasets. Corelyzer is easily expandable through the development of custom plug-ins. It can also pull data from the Web, as demonstrated at the workshop with a newly developed CHRONOS Web Data Portal plug-in.

2) The Workflow Database is a locally working database that allows for data access, Web services, and other databases, as well as synchronization between multiple CoreWall setups or databases, and it is intended for use in remote collaborations where data and images are being shared.

3) The Core-Log-Integration-Platform (CoreCLIP) application revises the SPLICER (stratigraphic composite builder) and SAGAN (core-log mapping) software that was previously a UNIX application used mainly by the ODP. CoreCLIP will provide a stand-alone application and a Corelyzer-ready plugin with many new features such as the ability to use images to assist stratigraphic composite building, an integrated text parser to improve data entry, contextual help and tutorials, and options to add new depth-correlation algorithms to improve composites and depth mapping results.

4) The CoreNavigator is a data discovery tool that has the ability to browse data in a 2- or 3-D geographic context. It uses VRML (Virtual Reality Modeling Language), to provide a visual means of comprehending cored stratigraphic datasets, integrated with seismic and oceanographic data when available. CoreNavigator displays are computed directly off databases. 
Prior to the current project funding, the Corelyzer software already had been under test-bed or prototype development for two years, and the developers had established a number of informal collaborations with several groups, including the Joint Oceanographic Institutions (JOI), the LacCore facility at the University of Minnesota, CHRONOS, and ANDRILL. The LacCore Facility has provided an important testing ground that drove the initial requirements and desired features of the software by getting the community to explore possible uses.

The two existing Corelyzer plug-ins were developed as a result of our ongoing collaboration with ANDRILL and CHRONOS. The first one is a connection between PSICAT, a sedimentary visual core description tool written for ANDRILL by CHRONOS, and the second plug-in is designed to connect Corelyzer to JANUS, the ODP database through the CHRONOS portal. Images and physical property data from multi-sensor core logger (MSCL) track systems can all be pulled on demand via a seamless Web service. This development will be tested in the 2006-2007 Antarctic field season of ANDRILL when we deploy Corelyzer at Crary Laboratory, McMurdo Station.

A separate collaboration with the Borehole Research Group of Lamont-Doherty Earth Observatory at Columbia University was initially an ODP legacy project to update the SPLICER and SAGAN stratigraphic software by making it a more portable, cross platform package for use on all IODP platforms and other coring communities. As part of the CoreWall project, the CoreCLIP software (Core-LogIntegration Platform) will be further enhanced. One possible enhancement presented at the workshop includes adding a dynamic, core-data mapping package, similar to the capabilities of the Match software, developed at Brown University (Lisiecki and Lisiecki, 2002).

One concern expressed at the meeting was the risk of CoreWall trying to do too many things for too many different groups this early in the development process. The foundation of the CoreWall Suite is its ability to integrate core images with all other data associated with the core and to display them in a scalable manner. It became immediately clear at the workshop that individual user communities would like to integrate new functionality and features into the CoreWall Suite. To address this desire, our team has created a plug-in structure that allows programmers to extend the functiona lity of the base software. For example, open-source tools

such as the National Institutes of Health's (NIH) image processing and analysis tool IMAGE-J could be made accessible through a plug-in. A capability to add depth-registered annotations to aid visual core description and a possible means for Internet collaborations were also popular items on the wish list. Core repositories such as the LacCore Facility in Minnesota were also looking at it as a means for tracking the sampling of cores, and educators and museum exhibit designers had many ideas for displaying primary scientific data with attached multi-media for classrooms and exhibits.

The most exciting part of the workshop was the convergence on the need for better data visualization by almost all communities represented. The timing of the CoreWall Project is driven in part and will be enhanced by co-developments of new global databases, global sample registration initiatives, data web portal developments like SEDIS (IODP), CHRONOS, dbSEABED, EarthChem, and others. CoreWall is envisioned to work with the larger community on a variety of levels and to empower all users to find, access, display, and use available data (Fig. 2). The goal is to allow users to do their own science, interact seamlessly with multiple remote databases to integrate new data, and even create unique sample IDs through IGSN for new samples and analyses.

The discussion of possible CoreWall uses in educational and museum settings produced many interesting ideas. Two of them were chosen as immediate targets. The first one was to create a set of "Core Best Hits" to be compiled within CoreWall complete with available MSCL data, smear slides, thin-sections, and comments. Example curricula co- 
developed by JOI, ANDRILL, or LacCore will be included in packaged downloads. Instructors can then use these examples to talk about climate change, plate tectonics, or the $\mathrm{K}-\mathrm{T}$ extinction. Another potential application was the use of CoreWall in an informal educational or museum setting. In such settings, the computer hardware will be configured with vertical screens to show the data in their proper orientation using a simplified trackball interface (Fig. 3). This configuration will be used in Water Planet, an NSF-funded, $550-\mathrm{m}^{2}$ traveling exhibit being developed by the Science Museum of Minnesota.

There was a general agreement among the workshop participants that the main functionality of the CoreWall Suite is well-suited to serve the visual integration needs of various communities that study cores. The visual integration capability alone would be a huge step forward for all of these communities if it can be accomplished in a robust, simple, and intuitive way.

The CoreWall Website (http://www.corewall.org) offers further information, a download link to the current version (0.68) of the Corelyzer software, and a Corelyzer Tutorial page. It also offers updates and news about the software and the project and presentations made at the workshop. A public CoreWall wiki page is available at http://sqlcore.geo.umn. edu/CoreVault/cwWiki/index.php/Main_Page for those interested in contributing comments or suggestions on the project development. A detailed CoreWall workshop report is forthcoming.

\section{Acknowledgements}

The CoreWall Consortium appreciates the generous funding of the JOI USAC to host this workshop and to have made available their Washington, D.C. offices for the meeting. Special thanks to Holly Given (JOI, Director USSSP), Robert Burger (JOI Associate Program Director, USSSP), Frank Rack (JOI, Director of Ocean Drilling Programs), Julie Farver, and Rob Wright for planning and technical support.

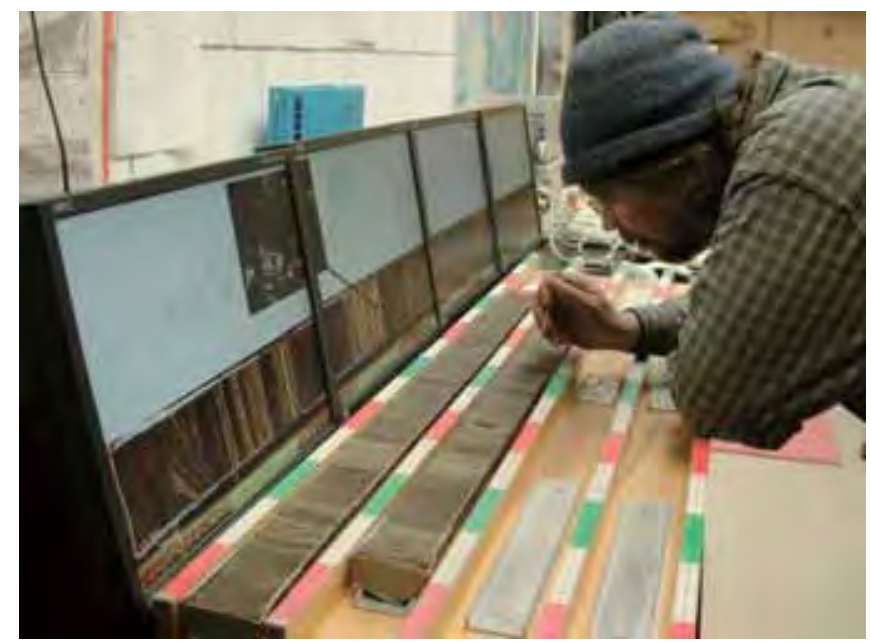

Figure 3. CoreWall setup for visual core description in laboratory.
Table 1. Developers of CoreWall Suite

Electronic Visualization Lab, University of Illinois at Chicago

Emi Ito, LacCore, University of Minnesota, Project coordinator

Paul Morin, LacCore, National Center for Earth-Surface Dynamics, University of Minnesota, Interface between programmers and users

Sean Higgins, L-DEO-Borehole Research Group at Columbia University, Oversees CoreCLIP development, interface to IODP

Arun Rao, Julian Chen, Jason Leigh, Andy Johnson, and Luc Renambot, Programmers and advisors for Corelyzer

Bill Kamp, IAGP Partners Limited, Inc., Programmer for CoreCLIP and Core Workflow Database

Chris Jenkins, INSTAAR, University of Colorado, Programmer for CoreNavigator

\section{Reference}

Lisiecki, L.E., and Lisiecki, P.A., 2002. Application of dynamic programming to the correlation of paleoclimate records, Pale-oceanography, 17(4), 1049-1060, doi:10.1029/2001PA000733.

\section{Authors}

The CoreWall Steering Committee:

S. Higgins (Lamont-Doherty Earth Observatory), S. Hovan (Indiana University of Pennsylvania), E. Ito (University of Minnesota), J. Miller (TAMU), P. Morin (University of Minnesota), C. Neal (University of Notre Dame), J. Ortiz (Kent State University), D. Quoidbach (Lamont-Doherty Earth Observatory), and W. Snyder (Boise State University, Idaho).

Contact: Emi Ito, Department of Geology, University of Minnesota, 310 Pillsbury Drive SE, Minneapolis, Minn. 55455, U.S.A., e-mail: eito@umn.edu

\section{Related Web Links}

http://www.corewall.org

http://www.evl.uic.edu/cavern/corewall/publications. php\#workshop

http://sqlcore.geo.umn.edu/CoreVault/cwWiki/index. php/Main_Page

http://www.laccore.org

http://www.chronos.org

http://portal.chronos.org/gridsphere/gridsphere?cid=tools_psicat http://www.andrill.org 